\title{
Online-Based Learning Problematics Between Needs, Readiness And Implications On The Purity Of Learning Outcomes
}

\author{
Eddy Saputra \\ Student of Doctoral Program, Islamic University of Jakarta \\ Correspondent: saputra2578@gmail.com
}

Submitted : June 28,2020 Revised : July 15, 2020 Published : July 30, 2020

\begin{abstract}
Online-based learning has been long echoed, online-based learning methods also have been implemented in several developed countries. In Indonesia it's self this method was already known as PJJ (distance learning). Does online based learning a necessity for students and teachers, while students and parents do not fully understand technology. then how the readiness technological infrastructure which includes the internet network, smartphones and laptops to support this learning, from the school and students. With the great distance between students and teachers, could online-based learning methods produce purity of learning outcomes. This paper will use qualitative methods, where data will be generated through observation, interviews and information from print and electronic media. The purpose of this paper is to map the problem of online base learning. at least, where one side of this method must be applied because of the pandemic period, on the other hand this method will not run optimally when conditions are normal.
\end{abstract}

Keywords: online based learning, needs, purity of learning outcomes

\section{INTRODUCTION}

During the Covid-19 pandemic, online learning was used by teachers and students. All levels of schools ranging from primary education to high levels are required to use this learning method. Online learning must be applied because there are health protocols that must be implemented so that the disease does not spread. Online learning has long been known as distance learning, the distance education system is an education system that covers all space, time and socio-economics that is able to open access to education for anyone, anywhere, and anytime.[1]

However, online learning is meaningless without obstacles. Components related to Education Infrastructure have not been fully obtained, not all students have technology media as the main component, other than that they are not supported by the internet network as a key to connecting to smartphones or laptops. In other hand the availability of internet services, another challenge that must be faced is cost . One of the Students state that to take online learning, they must pay more expensive to buy quota.[2]

Online-based learning must be implemented so that teaching and learning activities running well, other than because there are regulations for the community and others not to get together, because the learning process involves many people. Technology is the main supporting tool in learning activities. Online learning in its implementation requires the support of mobile devices such as smartphones, tablets and laptops which can be used to access information anywhere and anytime.[3] 
The pandemic forces all components of education to conduct online learning. Students and parents are forced to understand the technological devices, which are generally they known in their daily life. There are several applications which they used as online learning media such us Zoom, Google Meet, Google Classroom, etc.

Mobile phones which only able to be used for telephones and sending messages in the beginning, today have been turned into media which can change people's lives more easily and simply. All human needs already exist in one hand, but unfortunately the community does not able to maximize all the services provided therein. one of the obstacles is human resources who are still gaptek. Gaptek (a term used by people who cannot maximize technology). [4]

Smartphones and the internet are two things that cannot be separated when studying online. For some people in the city this is not a problem, internet signals are easy to reach. Internet data sellers also spread everywhere and plus there are contributions from internet service providers by providing free data packages for students. Unequal internet network infrastructure is still a major obstacle. Policy Expert Senior Director of General Education and Early Childhood Education, Ministry of Education and Culture, Mr. Suhadi said, teaching and learning infrastructure from home must be supported by good technology. Unfortunately, not everyone has the required infrastructure.[5]

In the aspect of online learning assessment, it is very difficult to determine assessment indicators because there are opportunities for students to be dishonest in doing the assignment. Internet access used for online learning facilities is also often used as a tool to find answers to student assignments. The learning process that is held online also has the potential for students to be assisted by parents in terms of answering questions given by the teacher. These processes have the potential to reduce the purity of assessment of student learning outcomes.

\section{METHOD}

This research uses qualitative research in this type of case study. The data source used in qualitative research is the appropriate environment. the main study is social conditions and events that occur, then learn and try to understand by staying in the location to be studied. This study aims to gain a general understanding of the problems that are happening in the community. Qualitative research explains the actual situation behind the phenomena which occur in a detailed and comprehensive manner.[6]

The case studies in this paper focus on aspects of online learning, starting with online learning needs and the purity of online learning outcomes, so that the data collected is sourced from the environment and people related to research. Creswell further revealed that if we will choose a study for a case, it can be selected from several study programs or study programs by using various sources of information which include: observation, interviews, audio-visual material, documentation and reports[7]

All data collected together in the form of triangulation must be interconnected because the process will produce conclusions from the results of the study. Triangulation is needed in an effort to check the validity of data to obtain perfection, data validity, accuracy of information, and originality of sources in qualitative research.[8] 
Online-Based Learning Problematics Between Needs, Readiness And Implications On The Purity Of Learning Outcomes

Saputra

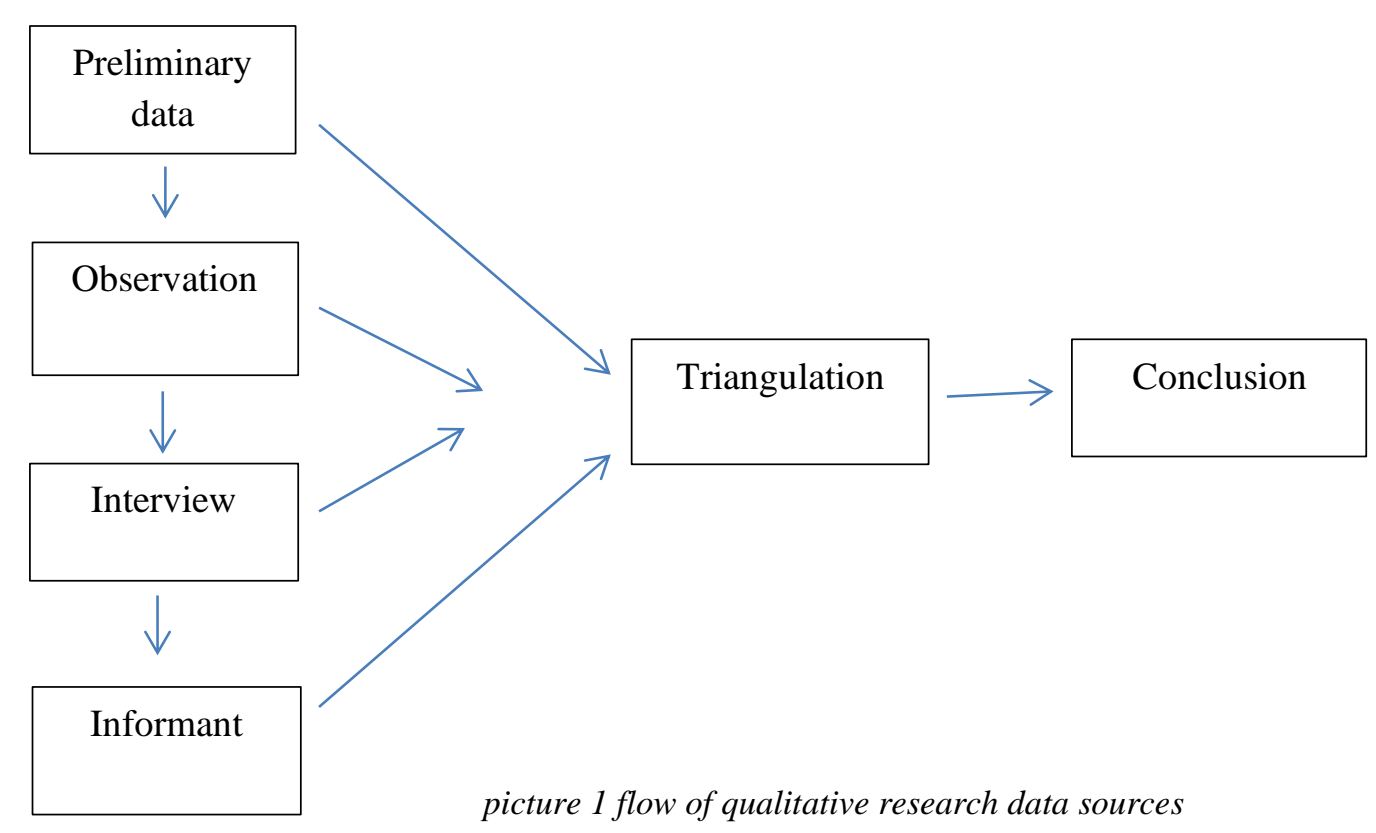

\section{RESULT AND DISCUSSION}

\section{Online learning problems}

Starting in 2020 online learning has been suddenly becoming a choice in the teaching and learning process. this is a big movement in education although in general people are faced with a pandemic outbreak. All teachers and students are required to master technology as a basic tool in online-based learning programs. This technology is very close to the community, but that does not mean the online learning process can run easily. Facts in the field are still many problems in the online-based learning process.

The use of technology has not been maximized among the people, the facilities inside it has not been fully used. This becomes one of the major obstacles when all activities must use technology, while in other countries technology is so close in supporting human activities. "Online learning has not become a culture in teaching and learning process in Indonesia. Many teachers and students are only rigidly conducting learning just to complete the syllabus of the curriculum," said Ferdiansyah as Commission X of the Indonesian Parliament. [9]

There are several findings in the field related to online learning problems or problems. A simple smartphone which has an extraordinary function. In fact there are still many parents think that smartphones are dangerous for children. Online games which are often played by children are of great concern parents in using smartphones. online games can make players forget time and become addicted. When experiencing addiction, it will be very difficult to get out of the game.[10]

There is a positive and negative impact on technology, in online learning technology is the most important tool. Parents must be able to change the mindset of the technology used in the online learning process. During this time the parents distinguish laptops with smartphones. When learning, the technology used is a laptop, but when a child is learning with a smartphone, the parent considers the child playing a game or something (not learning). In function, smartphone 
more flexible and can be purchased at a relatively affordable price. Even though this is affordable it also becomes one of the obstacles for low-income people.

The community must be faced with a pandemic that affects the economy in general. The high number of termination of employment (PHK) reduces the income of some people, the necessity to stay at home makes daily needs increase. Relatively affordable technology is hard for parents who don't give their children a smartphone from the start. While the needs are adjusted to the number of children, the same learning time but different materials require children to have their own smartphones.

\section{Online Learning Needs}

Online learning that is now being done does not depart from a plan that has been arranged. This program is carried out because it is imperative to keep the teaching and learning process running. Avoiding the crowd is an obligation for anyone, while the learning process involves many people, it was decided to learn online. Learning must be carried out without crowding. Online learning provides convenience across space and time, so students get flexibility in their time and place. Participants in online learning are greater than in traditional face-to-face classes.[11]

Teachers and students must experience a change in learning culture, where traditional learning sessions are face-to-face and in the classroom, now they must use technology and be far apart. Even though physically far away, the teacher and students are brought back to technology even though their closeness is only in cyberspace. This is a form of effort so that education continues even with limited conditions. In any case, education must continue in order to carry out the mandate of the law in order to educate the nation's children.

The necessity of online learning must be taken as a form of interrupted efforts and stopping the spread of the Covid-19. Online learning is also an effort to protect the health of students and teachers as well as those around the school. In addition to our concern for others, where as citizens we must also follow the government's call to keep our distance. With this it can be concluded that online learning is a necessity that must be met in the process of teaching and learning, although there are still problems here and there, now it is an effective way of learning solutions.

\section{Online Learning Readiness}

In the online learning process that is needed not only technology, there is an internet network that includes a single unit. Smartphones, laptops and the internet are a package for online learning. Even though the smartphone is close to the community in use there are still many people who have not maximized its function. Usage is still limited to telephone and texting. There is a change in the culture of learning to make people's perspective on smartphones have to be changed. That online learning the main tool is a smartphone or laptop which is also supported by the internet network.

The internet network is still an obstacle in online learning readiness. For some people who have been connected to the internet (wifi) from the beginning their homes can be said to be ready to face online learning. On the other hand the network also relies on signal strength, this is not an obstacle for urban communities, but this is still a major obstacle in the village. The problem is related to the infrastructure of the internet network that has not been evenly distributed. Infrastructure is a physical asset arranged in a system environment. So that it provides important 
public services. Infrastructure provides support and services that will be used and utilized for the continuity of a system.[12]

In terms of learning readiness students and teachers have begun to get used to but the pandemic period inhibits readiness from the other side, the pandemic period also has an impact on the global economy. Schools in general have already set up an internet network, but because learning is carried out at home, teachers and students must bear the burden of the cost of purchasing a data package. All school assignments are sent via Whatsapp in the form of pdfs and videos, to open both files can use up large data packages. Not to mention the specifications of the smartphone is very influential in receiving files sent.

From the phenomena that occur can still be found several times in dealing with the learning process online. From this aspect of readiness is something that must be faced without any choice. Departing with all the limitations, online learning must be supported by mature readiness, readiness of human resources, technological readiness and internet network infrastructure readiness that is evenly distributed from Sabang to Merauke, until finally education can be enjoyed wherever the nation's children are.

\section{Purity of Online Based Learning Outcomes}

Pure learning outcomes become an indicator to determine the success or failure of the learning process. This is a form of efforts to teach students the values of honesty. At school students are seriously required to get pure grades as a condition of graduation or graduation. Even though the final grade is an amalgamation of each learning process, those values are obtained through a test administered by the test supervisors. Plus parents have never been involved in the learning process at school.

Some of the findings of online based learning during the pandemic can reduce the purity of student learning outcomes. Parents are directly involved, even parents become very important people because the teachers deliver and send assignments through their smartphones which are then passed on to their children. Once the assignment is completed, before the assignment is sent to the teacher the parents make sure again that there are no mistakes in answering, while this is never done when studying face to face.

Parents are directly involved in the learning process which will have an impact on students' learning independence. Ideally, the learning process can be independent, because with independence students will be accustomed to solving problems. Independence can be obtained by students whose pure learning outcomes are obtained. Learning outcomes obtained are difficult to forget and can be utilized in a variety of situations that fall into certain categories. The ability to solve problems is a very important learning outcome and must be mastered by students in addition to learning outcomes in the cognitive aspects.[13]

Researchers found cases in the field of student online learning entered through 2 smartphones. The teacher sends the assignment link then the assignment link is carried out on another smartphone then sent. After sending the values will appear and the answers are wrong and correct. If there is an error in answering, students repeat in order to get a perfect score and then send it using a cellphone whose number has been registered with the teacher. The current online learning process is indeed inseparable from their parents. Teachers' access in assigning assignments still requires parents. 
The next problem is the smartphone used for learning is also often used as a tool to find answers. Weak learning supervision makes it very difficult to get pure learning outcomes. Compliance and obedience to students can be done when there are people who are also involved in supervision, when the supervisor is not there, the potential for violations is huge. So that it can be concluded the purity of learning outcomes in online learning is not entirely considered pure.

\section{CONCLUSION}

There are still many problems in the online-based learning process. The problem in it involves the readiness of human resources for the use of technology that is still minimal. However, the need for online learning provides a solution to keep the learning process going, in the midst of the government's distance learning. In the aspect of online learning readiness of teachers and students, there are several obstacles, such as readiness to start studying with students because there is no definite time when entering and going home like normal school time. Low smart phone specification, economic problems due to this process in the pandemic which had an influence on the people's economy, limited data packages and other technical problems.

Online learning can also reduce the value of purity on learning outcomes. Parents of students are still dominantly involved from the beginning to the end of the learning process, and this is very influential on students' independence in learning. At this time the online learning process still leaves problems both technical and non-eclectic, if this is to be implemented it requires careful planning with regard to also the infrastructure that supports online learning.

\section{REFERENCE}

(Indonesia / Ristekdikti). (2016). Guide to Implementing Distance Education 2016. In the Director General of Learning and Student Affairs Ministry of Research, Technology and Higher Education.

Firman, F., \& Rahayu, S. (2020). Online Learning in the Middle of the Covid-19 Pandemic. Indonesian Journal of Educational Science (IJES). https://doi.org/10.31605/ijes.v2i2.659

Gikas, J., \& Grant, M. M. (2013). Mobile computing devices in higher education: Student perspectives on learning with cellphones, smartphones \& social media. Internet and Higher Education. https://doi.org/10.1016/j.iheduc.2013.06.002

Nurmila, N., Maslani, Tarsono, \& Satriah, L. (2020). Optimization of Online Learning at UIN SGD Bandung in an Effort to Stop the Spread of Corona Virus. Digital Library, UIN Sunan Gung Djati, Bandung.

Anisyah Al Faqir, Uneven Internet Access Becomes an Obstacle to Implementing Learning from Home in the Middle of Pandemic, Merdeka.co.id 20 May 2020 14:43

Saputra, E. (2019). Alternative Non-Formal Education in Improving Morals in Children Through Mosque-Based Education (Madrasa Diniyah / Religious Schools). SAP (Arrangement of Educational Articles). https://doi.org/10.30998/sap.v4i2.4853

Creswell, J. W. (2013). Qualitative Inquiry and Research Design. In Qualitative Inquiry and Research Design.

Lexy J. Moleong, D. M. A. (2019). Qualitative Research Methodology (Revised Edition). PT. Teens Rosda Works. https://doi.org/10.1016/j.carbpol.2013.02.055 
Online-Based Learning Problematics Between Needs, Readiness And Implications On The Purity Of Learning Outcomes

Saputra

https://www.kompas.com/edu/read/2020/05/18/212505271/seminar-umj-learning- distancefar-belum-jadi-culture-process-learning-in?page $=$ all.

Suplig, M. A. (2017). The Effect of Online Game Addiction for Class X High School Students on the Social Intelligence of Private Christian Schools in Makassar. Jaffray Journal. https://doi.org/10.25278/jij1.v15i2.261

Rio Adriyanto, A., Santosa, I., \& Syarief, A. (2020). Instillment of value in online college teaching materials. Journal of Social Theory and Practice Learning. https://doi.org/10.17977/um022v5i12020p039

Hendrastomo, G. (2008). Learning Dilemmas and Challenges E-learning 1 (The Dilemma and the Challenge of. Learning Scientific Magazine.

Nasution. 2011. Various Approaches in the Learning and Teaching Process. Jakarta: Earth Literacy. 